\title{
¿De qué hablamos cuando hablamos de justicia social en educación?: el análisis ideacional como estrategia de análisis crítico del discurso*
}

\author{
Fernando Murillo**
}

\begin{abstract}
Resumen
El siguiente artículo surge de una investigación en el campo del currículum, y particularmente, en el ámbito de la formación inicial de profesores. Considerando las actuales condiciones de desigualdad y otras formas de injusticia generadas y sostenidas por políticas neoliberales, este trabajo propone reconsiderar la noción de justicia social como componente de las propuestas formativas de futuros docentes. Para esto, se propone el Análisis Ideacional como una estrategia metodológica de aproximación al estudio de los discursos de justicia social, a fin de proveer una herramienta práctica para revisar los contenidos y nivel de operacionalización que alcanzan las declaraciones ligadas a la justicia social en las instituciones de formación. El trabajo termina problematizando los hallazgos que surgen del ejercicio metodológico, a fin de proveer elementos que aporten a repensar las propuestas curriculares.
\end{abstract}

Palabras clave: Análisis ideacional, justicia social, curriculum, Análisis Crítico del Discurso.

\section{What do we talk about when we talk about social justice in education? The ideational analysis as a strategy of critical discourse analysis}

\begin{abstract}
The following piece stems from a research in the field of curriculum, and specifically, in the area of teacher education. Considering as a starting point the current conditions of inequality and other forms of injustice generated and sustained by neoliberal politics, this article proposes the consideration of the notion of social justice as a component for the curriculum of teacher education. For this, we propose an Ideational Analysis as a methodological strategy to approach the examination of the content and level of operationalization of declarations related to social justice within institutions of higher education. The article ends by problematizing the findings that emerge from the methodological exercise, with the purpose of providing elements to rethink the curricular proposals.
\end{abstract}

Keywords: Ideational analysis, social justice, curriculum, Critical Discourse Analysis.

\footnotetext{
* $\quad$ Este artículo es una síntesis de la investigación realizada en el magíster en Ciencias de la Educación y Currículum de la Universidad Católica de Chile.

** PhD (c) en Estudios Curriculares. Facultad de Educación. Universidad San Sebastián. Santiago, Chile.fernando.murillo@alumni.ubc.ca
} 


\section{Introducción}

El trabajo en torno a la conceptualización de la justicia social, en general, y en particular en lo que respecta a su utilización en el ámbito educativo, resulta especialmente complejo. Esto porque el término aparece muchas veces como ambiguo, o porque los enfoques metodológicos que se utilizan para su estudio no son explicitados de manera clara (Cochran Smith, 2004, 2008; Zeichner, 2009; MacDonald, 2005). Así, y considerando que el uso y significado de los conceptos difieren dramáticamente dependiendo de los territorios epistemológicos desde los que se pronuncian (Murillo, 2011), una pregunta válida que puede surgir tras extensas revisiones bibliográficas es, al final del día, ¿de qué estamos hablando cuando hablamos de justicia social? Particularmente, ¿de qué modo aparece el interés por la justicia social en la propuesta formativa de un programa de formación docente?

En este trabajo se ejemplificará una modalidad metodológica para aproximarse a la investigación de los discursos de justicia social en el ámbito universitario. Aún cuando el alcance de la investigación no pretende más que establecer aspectos generales en relación con el tema, el ejercicio descrito es útil para mostrar el modo en que una universidad concibe su noción de justicia social, o en definitiva, de lo que hablan cuando hablan de justicia social. El propósito es mostrar una aproximación práctica-metodológica desde un Análisis Crítico del Discurso (ACD) y sus hallazgos en cuanto a la concretización de las enunciaciones que hace una institución en torno a sus fines formativos, abriendo espacios para avanzar en las posibilidades de traducción efectiva del interés por la justicia social en elementos curriculares organizados, intencionados y evaluables. De este modo, se trata de un esfuerzo por hacer de la esperanza algo práctico (McInerey, 2004).

En este contexto, la postura sobre la que se sostiene el estudio asume el currículum como una construcción socio-cultural que se organiza e intenciona en propuestas de formación, las que -mediadas por prácticas discursivas de poder- impactan en una conformación de identidad en los sujetos que incorpora.

El interés por el estudio curricular de la formación docente en este trabajo se relaciona no con las ya familiares preocupaciones por sus aspectos administrativos o asuntos metodológicos, sino más bien con el desarrollo de una política cultural que posibilite compresiones y transformaciones a la luz de consideraciones sobre preguntas 
fundamentales acerca de sus sentidos e implicancias. Más aún, se trata de un proyecto que se propone comprender, articular y potenciar los lenguajes de crítica y de posibilidad en la formación de profesores, a manera de posibilitar las condiciones para que parte importante de su postura y saber profesional movilice competencias para denunciar situaciones de injusticia, y anunciar espacios de posibilidad y transformación por medio de una práctica profesional comprometida e intencional.

¿Qué implicancias tiene para la formación de profesores asuntos como el concepto de conocimiento, sus formas de transmisión, y la función que estas cumplen en la configuración de sujetos y contextos?

¿Para qué es la educación? ¿De qué manera nos prepara para una democracia radical y plural? ¿De qué forma ayuda a cerrar la brecha entre ricos y pobres? ¿Cómo establece las condiciones para la validación y valoración de lo distinto? Asuntos como estos - propios de la pedagogíason absolutamente inseparables de las preguntas relativas a la justicia social en el contexto educativo.

Investigar las respuestas que se dan a preocupaciones de esta índole supone necesariamente indagar en contextos particulares en los que emergen los discursos y prácticas, puesto que la noción de justicia - como otras temáticas epistémico-políticas ligadas a la educación- no están configuradas por leyes naturales, sino más bien por creencias, compromisos y disposiciones que se dan en el contexto de una práctica institucional.

\section{Metodología}

Una de las preguntas que se abordó en la investigación desde la que surge este artículo es:¿Cuál es el contenido ideológico del discurso de una universidad en torno a la justicia social y la formación inicial de profesores? Dado que el uso de los conceptos no es neutro, sino que se pronuncian desde territorios epistémico-ideológicos diversos, con intencionalidades distintas y - por ende- con efectos particulares que emergen de ese posicionamiento, resulta central conocer cuáles son los supuestos, compromisos, adherencias ético-políticas e ideas que están operando al momento de seleccionar y enunciar discursos en torno a la justicia social y su relación con la formación de profesores.

La metodología para lograr este propósito supuso seleccionar tradiciones y enfoques particulares que resultaran coherentes con la 
naturaleza del objeto estudio y eficaces en la capacidad de respuesta a la pregunta planteada. De este modo, se optó por un diseño investigativo bajo el paradigma de investigación cualitativa, que admite la comprensión de fenómenos desde lógicas lingüísticas y no solamente desde aquellas reducidas a explicaciones alfanuméricas; la focalización de la investigación en un estudio de caso que permitiera describir y comprender una realidad particular en profundidad; y el trabajo analítico desde un enfoque de Análisis Crítico del Discurso (Fairclough, 2003)al interior del cual, y para efectos de este trabajo, se optó por una función particular, que es el Análisis Ideacional derivado de la perspectiva Sistémico - Funcional (Martin y Rose, 2003).

En la tarea de reconocer rasgos que dan cuenta del posicionamiento de los discursos estudiados, presentes en su selección léxica, el Análisis Ideacional en Martin y Rose (2003) resultó útil y eficaz para este trabajo, en el sentido que reconoce el lenguaje en y con su contexto social y cultural. En otras palabras, no escinde el lenguaje de la práctica social que (se) constituye, por lo que el texto - que media el discurso y la práctica- es un modo de acceder y analizar aspectos de la cultura de los participantes. Desde ahí que para estos autoresal momento de hacer análisis textuales está la posibilidad de identificar significadosque construyen experiencia no solo más allá, sino que también "más abajo de la cláusula" (2007, p. 96). De esta manera, en este trabajo el objeto de análisis no queda circunscrito a la oración, ni a la cláusula, sino más bien a enunciados como unidades de significado.

En cuanto al caso de estudio, se seleccionó una universidad en Santiago de Chile que presentaba características y elementos discursivos particulares que hacían referencia a un interés por enfocar el trabajo desde una perspectiva de justicia social. Al interior de esta institución, se trabajó con textos escritos oficiales de circulación pública (Acta de Fundación y Discurso de Inauguración de la Universidad) y el discurso que surge de la voz de académicos directivos de su Facultad de Educación, por medio de una entrevista grupal. El proceso de selección y las características de estos textos son presentados más adelante. 


\subsection{Acerca del ACD: entre teoría y método}

El desarrollo de una investigación implica -generalmente- la delimitación de un problema u objeto o a ser estudiado, la construcción de un cuerpo teórico que permita la comprensión de la situación y posterior interpretación de los datos y, por último, la selección de una estrategia metodológica que guíe la recogida de datos y el análisis de los mismos. Pero cuando la problemática está ligada al estudio del discurso, las selecciones y delimitaciones se tornan un asunto complejo (Volosinov, 1986). Tal complejidad radica no solo en la multiplicidad de elementos que lo estructuran (aspectos léxico-semánticos, gramaticales, fonéticos, etc.), o en la diversidad de tradiciones filosóficas del lenguaje que definen sus focos de atención, sino que fundamentalmente por su nexo inextricable con el pensamiento y el medio socio-cultural que construyen (Wertsch, 2002).

Aunque el desarrollo e influencia de las metodologías cualitativas tradicionales podrían dar pie a considerar al ACD como una decisión de tipo metodológica,sus atributos (y atribuciones) críticas dan cuenta de la necesidad de problematizar el enfoque en la doble dimensión que abarca. Esta doble dimensión implica llegar a comprenderlo y asumirlo en su naturaleza tanto como aproximación teórica a la investigación, así como enfoque que guía las decisiones en cuanto a métodos en relación a las necesidades y preguntas a resolver por medio del estudio. Para esto, la tesis a la base es que, de acuerdo con su mismo nombre, el Análisis Crítico del Discurso es, en primer lugar, crítico y en segundo lugar lingüístico, lo que supone un posicionamiento epistémico-teórico previo que -en conformidad con la naturaleza de la problemática que se estudiará- selecciona métodos coherentes tanto para el objeto como para el enfoque que lo sustenta como problema. En palabras de Fairclough, el ACD es, por un lado, "una perspectiva teórica que versa sobre el lenguaje - o sobre la semiosis, y por otro, un elemento o "momento" del proceso social material" (2003, p.179). En esta ambivalencia entre teoría/método se hace posible una relación de transdisciplinariedad con otras teorías y métodos, lo que permite en el ACD un desarrollo complejo que sobrepasa los límites entre teoría y método.

La relación transdisciplinar, dialéctica y compleja hace que el ACD sea comprendido -de acuerdo con Van Dijk- como una "perspectiva, crítica, sobre la realización del saber: es...un análisis del discurso efectuado "con una actitud" (2003, p. 144), y luego agrega que el ACD "no nos brinda un enfoque ya hecho que nos indique cómo hacer el análisis social, sino 
que...para cada estudio debe procederse al completo análisis teorético de una cuestión social, para seleccionar qué discurso y qué estructuras sociales analiza y relaciona" (p.147).

Por lo tanto, los métodos son seleccionados necesariamente según las preguntas que se espera responder, la naturaleza de los textos (discursos) y los intereses que guían la acción del investigador. Fundamentalmente, el estudio desde el ACD se justifica cuando resulta apropiado a los objetivos de la indagación, y cuando está en consonancia con la actitud, las creencias y los compromisos ligados a un interés crítico y postcrítico.

Para lograr responder a la pregunta planteada en este trabajo (encaminada a situar y describir los contenidos ideológicos de los discursos sobre la justicia social en la formación inicial docente en una universidad), se requiere de un enfoque particular de análisis crítico que centre los esfuerzos en los sentidos y modos de conciencia que materializan el discurso oficial de la Universidad, en lugar de un análisis lingüístico propiamente tal. De ahí la opción por una perspectiva inspirada en Foucault, quien moviliza la indagación y las preguntas orientadoras de la investigación hacia la comprensión del carácter epistémico-ideológico de las prácticas discursivas, describiendo sus contenidos subyacentes y el modo en que un ejercicio de poder posibilita la existencia, validación y aceptación de ese discurso por sobre otros, confiriéndole efectos de verdad.

Por consiguiente, se consideró adecuado trabajar desde esta perspectiva el análisis descriptivo de los contenidos ideológicos y racionalidades presentes en textos particulares al interior de la Facultad estudiada, puesto que la orientación de los docentes formados y su sentido de rol se imbrica a los discursos que la institución y sus directivos declaran y decretan. En palabras de Foucault, son estas prácticas discursivas las que "forman sistemáticamente los objetos de que hablan" (1979, p.81).

\subsection{Corpus de textos para el análisis}

La cantidad de datos muestrales no representa aquí un asunto de interés, puesto que, en lugar de levantar explicaciones basadas en grados de representatividad (junto a los otros supuestos de alatoriedad y generalización propios de una racionalidad positivista), se busca identificar recursos particulares que aporten mayor riqueza y pertinencia de información en torno al fenómeno estudiado con tal de reconstruir insights de mayor 
profundidad y que den cuenta de las intencionalidades subyacentes en discursos institucionales.

Teniendo en consideración los conceptos clave para este estudio como lente preliminar, la selección de los textos se enmarcó en criterios que permitieran cautelar un proceso metodológicamente riguroso, los que se indican a continuación:

a) Estatus institucional de los textos, siendo producidos, diseminados y utilizados por estamentos oficiales y permanentes de la Universidad.

b) Carácter público y de libre acceso.

c) Relevancia de los textos para intereses formativos en cualquiera de sus formas y dimensiones posibles.

d) Representatividad de un posicionamiento institucional autoritativo en torno a las directrices y énfasis que adoptan sus programas formativos.

Considerando estos cuatro criterios, los tres textos institucionales que se seleccionaron fueron los siguientes.

1. Acta de Fundación de la Universidad.

2. Discurso de Inauguración de la Universidad.

3. Entrevista a directores de programas de la Facultad de Educación.

Tanto el Acta de Fundación como el Discurso de Inauguración tienen relación con los posicionamientos, definiciones y directrices generales de la institución en todas sus dimensiones formativas. En términos de género discursivo, si bien están en un soporte escrito, se presume que ambos fueron redactados para ser leídos ante una audiencia particular.

El tercer texto, en tanto, da cuenta de las interpretaciones o -siguiendo a Fairclough (2003)-“recontextualizaciones” que hacen el decano y los directores de programas, de las directrices institucionales en el campo más específico de la formación de profesores en la Facultad de Educación.

\subsection{Caracterización general de los textos}

\section{Acta de Fundación:}

En este documento, si bien corto en extensión (20 líneas) se encuentran las claves de mayor peso ideológico que delinean el carácter de la propuesta formativa de la institución estudiada. La definición del carácter de la actividad formativa se aprecia en unidades de sentido que apuntan 
al tipo de conocimiento (en qué consiste) y cómo se transmite (de qué manera y con qué fin), definiendo asimismo el carácter y tipo de relaciones que se intencionan en los sujetos participantes, siendo estos aspectos centrales de una propuesta curricular. El peso ideológico de este texto se reconoce en primer lugar porque -de acuerdo con su género- se trata de un documento de carácter prescriptivo de la finalidad de la institución y lo distintivo de su funcionamiento. En esta misma línea, y de acuerdo con Torres (1998), la ideología se reconoce toda vez que un discurso define un "quiénes somos", "cómo es el mundo", qué es lo "bueno, correcto y justo", y delinea las "posibilidades y sentidos de cambio". En otras palabras, se trata de un texto que enmarca el "campo de juego" de la institución. De esta manera, el Acta de Fundación se vuelve un ejemplo claro del rol del discurso en la constitución de identidades sociales, de relaciones sociales y de sistemas de conocimiento y creencias (Fairclough 2008, p. 172).

\section{Discurso de Inauguración:}

En términos de función, un discurso se pronuncia con distintas finalidades, como la de comunicar, promulgar, declarar, inaugurar, etc. Un factor común es que en las ocasiones en que se pronuncia un discurso es el sentido de legitimación que otorga a esa ocasión/institución la práctica social en que alguien pronuncia palabras frente a otros marcando hitos (aperturas, cierres, etc.) En un contexto institucional formal, las estrategias de selección léxico-semánticas contribuyen a lo que Van Leeuwen (2008) refiere como parte de un proceso de legitimación de prácticas sociales. Así, este texto, de una extensión de 6 páginas y que incluye un decálogo del estudiante que espera formar, responde de cierta manera a las preguntas tácitas a la que refiere este tipo de práctica social: ¿Por qué deberíamos hacer esto? ¿Por qué deberíamos hacerlo de esta manera?(Van Leeuwen, 2008, p.105). El discurso de inauguración se relaciona intertextualmente con el Acta de Fundación, proveyendo contextos y desarrollos más elaborados en torno al carácter y propósitos de la propuesta formativa.

\section{Entrevista grupal a decano y directores de programa:}

El texto de la entrevista es de particular importancia para este estudio, puesto que convoca las voces de personas que toman decisiones tanto en el ámbito de la organización de la formación de profesores, como en la docencia directa, y en investigaciones relacionadas a ella. Al tratarse 
de actores investidos de autoridad para la toma de decisiones y tienen contacto directo con los estudiantes que forman, su discurso constituye un insumo de especial interés para responder a las preguntas de este estudio. Esto, porque su discurso constituye una recontextualización de la perspectiva de justicia social y formación de profesionales de la Universidad. Vale decir, representa el modo en que estos actores interpretan, significan y apropian los principios institucionales, por medio de prácticas, imágenes y palabras que despliegan en la dirección que dan a la formación de docentes. La entrevista-de carácter semiestructuradaestuvo conformada por cuatro participantes, incluyendo al decano de la Facultad de Educación y tres académicos directores de programas al interior de la Facultad. La duración de la entrevista fue de 90 minutos, y se guio por medio de 7 preguntas orientadoras:

a) ¿Qué caracteriza la formación de esta Universidad? ¿Qué énfasis tiene la enseñanza impartida?

b) ¿Cómo se entiende la orientación social/pública de la Universidad en la Facultad de Educación?

c) ¿Cómo se ven esos énfasis en el diseño de los cursos y en la sala de clase?

d) Como formadores, ¿de qué manera conceptualizan la práctica de la formación de docentes para la justicia social?

e) ¿Qué ocurre con las nociones de justicia social de la Universidad de cara a los actuales énfasis en evaluaciones estandarizadas, competencias y otras demandas propias del mercado?

f) ¿Qué rol juega el estudiante en su formación como profesor?

g) ¿Cómo se evalúa?

\subsection{Esquema de Análisis}

El análisis de los textos se planteó en un esquema de tres fases organizadas secuencialmente, desde los aspectos más generales del discurso hacia un análisis más detallado de los enunciados. Cada fase desarrolló una tarea distinta, que en conjunto permitieron alcanzar el objetivo general de la investigación (ver Tabla 1). 
Tabla 1. Fases de análisis.

\begin{tabular}{|l|l|}
\hline FASE & FOCO y TAREA \\
\hline $\begin{array}{l}\text { Fase 1 } \\
\text { Género Discursivo }\end{array}$ & $\begin{array}{l}\text { Género Discursivo: Segmentación de acuerdo con la orga- } \\
\text { nización estructural del discurso, respetando la naturaleza } \\
\text { sociocultural del género discursivo. }\end{array}$ \\
\hline $\begin{array}{l}\text { Fase 2 } \\
\text { Análisis temático } \\
\text { de enunciaciones }\end{array}$ & $\begin{array}{l}\text { Racionalidades Curriculares: Organización de segmentos } \\
\text { temáticos (unidades de sentido) al interior de cada ma- } \\
\text { crosegmento, en una matriz de Intereses Constitutivos del } \\
\text { Conocimiento (Habermas 1972,1974; Grundy 1998) }\end{array}$ \\
\hline $\begin{array}{l}\text { Fase 3 } \\
\text { Análisis textual }\end{array}$ & $\begin{array}{l}\text { Contenido del discurso: Identificación de las huellas } \\
\text { discursivas que materializan las categorías. Análisis micro, } \\
\text { utilizando categorías lingüísticas. }\end{array}$ \\
\hline
\end{tabular}

Para efectos de este artículo, nos enfocaremos en la tercera fase del esquema -que utilizó la Metafunción Ideacional- la que se abocó al análisis textual de huellas discursivas que permiten visualizar el contenido y posicionamiento ideológico de los discursos institucionales respecto a la justicia social.

En términos teórico-prácticos, esta etapa supone reconocer al lenguaje no como un fenómeno autónomo, sino más bien como una práctica de función y de organización social. De este modo, recurrimos a la palabra para identificar en ella -y en sus silencios- el paisaje ideológico desde el que se pronuncia y desde el que cobra sus sentidos, puesto que en estas se inscriben los compromisos de los sujetos, sus creencias acerca de lo posible, lo deseable. Reconocemos, junto a Volosinov, que "el dominio de los signos es el dominio de las ideologías y la palabra es el signo ideológico por excelencia” (en Ávila y Medina 2012, p.232).

En la tarea de reconocer rasgos que dan cuenta del posicionamiento de los discursos estudiados, presentes en su selección léxica, la perspectiva Sistémico Funcional de Martin y Rose (2003) resultó útil y compatible con este trabajo, en el sentido que reconoce el lenguaje en y con su contexto social y cultural.

Un primer recorte que hacemos desde esta propuesta de carácter sistémico funcional es la selección de uno de esos recursos en particular: la Metafunción Ideacional, la que, en términos generales, es la que pone el foco en el contenido del discurso, la representación de la experiencia. En palabras de Martin y Rose, la función Ideacional se enfoca en 
qué tipos de actividades son desarrolladas, de qué manera se describen a los participantes que realizan esas actividades, de qué modo se clasifican y cómo están compuestas. La Ideación se encarga de ver cómo nuestra experiencia de "realidad", tanto material como simbólica, es construida en el discurso. (2003, p.66).

Ante la pregunta por el modo en que construimos esta experiencia en textos, estos autores afirman que este proceso se construye por medio de una secuencia de "figuras". Ellas se pueden referir a procesos (hacer, decir, sentir, ser), participantes (personas o cosas) y circunstancias. En el contexto de la investigación realizada, se consideró la figura de procesos, la que se compone de la descripción del hacer, significar (decir, sentir) y ser (cualidad, clase, identidad, existencia).

Esta selección resulta pertinente en cuanto la conceptualización de justicia social (que, desde la perspectiva del texto, aparece como una figura metafórica) requiere ser abierta, o desempacada, en los diversos elementos presentes en el texto que, en su conjunto, dan cuenta de la noción de justicia. Para esto, se explora entonces la construcción de la noción de justicia en la descripción léxica de sus procesos (lo que se dice, hace y siente respecto a ella) y sus cualidades (qué es lo que hay, qué es lo que debiera ser, cómo se le adjetiva).

El foco de atención para este estudio se dirige principalmente a estos elementos de patrones básicos de (re)construcción de la experiencia, sin embargo -y aunque representan los recursos centrales para la especificación de esa experiencia- Martin y Rose (2003) advierten que estos son solo una parte de las estrategias que utilizamos en el lenguaje para esa representación. Otros elementos adicionales se hacen necesarios para acercarse a los significados con los que se construye una experiencia.

En ese sentido, un segundo recorte metodológico -y que viene a complementar el análisis anterior- es la identificación y clasificación de los enunciados utilizando las Modalidades Enunciativas propuestas por Álvarez (2001), puesto que permiten reconocer los énfasis que se le atribuyen a estos. Las modalidades son: alética (posibilidad), deóntica ("deber ser", obligatoriedad), epistémica (operaciones mentales, "saber", “creer"), volitiva (voluntad) y apreciativa (juicios valorativos). 
Así, el análisis de esta fase se configuró del siguiente modo (ver Tabla 2).

Tabla 2. Esquema de análisis ideacional.

\begin{tabular}{|l|l|l|}
\hline Metafunción Ideacional & \multicolumn{2}{|l|}{} \\
\hline Figura Metafórica & Proceso & Hacer \\
& Significar \\
& Ser \\
\hline Modalidades del enunciado & Aletica \\
& Deóntica \\
& Epistémica \\
& Volitiva \\
\hline
\end{tabular}

\section{Resultados}

Para la fase investigativa que aquí se describe, interesaba explorar huellas discursivas materiales más precisas en el discurso, a fin de situar su posicionamiento con respecto a lo que consituye una opción por la justicia social, y los modos en los que se operacionaliza en la práctica curricular.

\subsection{Modalidades Enunciativas}

A partir del esquema antes señalado, se realizó un análisis de los enunciados del corpus de textos en términos de sus modalidades enunciativas las que, en términos de frecuencia, se agruparon de la forma que exponemos a continuación.

Tabla 3.

\begin{tabular}{|l|l|l|l|}
\hline Modalidad & Acta Fundación & $\begin{array}{l}\text { Discurso } \\
\text { Inauguración }\end{array}$ & Entrevista grupal \\
\hline Alética & - & - & 2 \\
\hline Deóntica & - & 11 & 5 \\
\hline Epistémica & - & 1 & 19 \\
\hline Volitiva & 6 & 8 & 1 \\
\hline Apreciativa & - & - & 6 \\
\hline
\end{tabular}

Aunque la frecuencia de aparición de ciertas categorías en un texto no siempre es determinante de los asuntos de mayor relevancia para una investigación o para emitir un juicio valorativo sobre ellas, en este caso la manera en que se distribuyen las modalidades enunciativas en los tres textos analizados resulta de interés por los siguientes dos motivos. 
En primer lugar, los recursos lingüísticos utilizados en cada texto resultan coherentes y esperables de ser utilizados en cada género discursivo, a fin de llevar a cabo la función de ese género. Por ejemplo, para el caso del Acta de Fundación (cuya función es instalar las motivaciones para la apertura y funcionamiento de una organización) las únicas modalidades encontradas son las de tipo volitiva, las que en un texto de veintelíneas, aparecen a razón de dospor cada párrafo. Se logra apreciar entonces que el peso comunicativo de este texto está en definir los propósitos y carácter de la organización que se funda.

Ejemplo:

L2: "para contribuir al desarrollo de un Chile próspero, justo y solidario".

En el caso del texto del Discurso de Inauguración, se aprecia un balance entre la voluntad de lo que se espera (función volitiva) con un mayor acento en la modalidad deóntica, vale decir, la definición de aquello que la institución asume como tarea y foco de su trabajo.

Ejemplo:

Volitiva: P29: "esperamos formar hombres y mujeres colaboradores de Dios, que comprenden su profesión como una misión y posibilidad de servicio, que existen para los demás y que no busquen en primer lugar su propia realización ni su prestigio".

Deóntica: P34: "es indispensable que se estudien los mecanismos que generan injusticia y que se tenga contacto real con los marginados, con los más pobres y con los que más sufren, con la verdad de Chile".

En el texto de la entrevista a los académicos, aparecen muestras de las cinco funciones, donde la modalidad más sobresaliente es la epistémica, precisamente porque es el espacio de diálogo en que los participantes dan cuenta de los sentidos y comprensiones detrás de sus decisiones en la dirección y docencia de los programas pedagógicos.

Ejemplos:

Epistémica: L244-250: "creo que hay una opción fundacional porque los estudiantes, especialmente de pedagogía, que son... más vulnerables en relación a los estudiantes universitarios tradicionales, vengan acá, porque acá creemos que es justo y democrático que ellos tengan una oportunidad de estudiar, y yo creo que eso es muy inspirador del sentido inicial de la Universidad". 
Epistémica: L634-641: “yo creo que los cabros jóvenes que entran al programa enganchan con esto, porque finalmente, es un discurso con sentido, con proyección social, es decir, usted...es un sujeto que toma decisiones, que participa de lo público, que tiene que trabajar por la justicia, o sea, se llena de contenido tu quehacer...".

En segundo lugar, otro aspecto interesante es que las modalidades enunciativas que aparecen con mayor frecuencia en los tres textos son la deóntica y la epistémica. De esta manera, el acento comunicativo desde el que se instala el discurso es uno de carácter autoritativo, pues, en lugar de hacer descripciones apreciativas acerca del estado de cosas, o la enunciación de deseos de que algo ocurra, el contenido de los textos define de manera clara aquello que "debe" o "debería ser" en al ámbito de la formación de profesionales (deóntica), lo que se asienta sobre la base de un "saber" tanto epistémico como doxático ( saber y opinión).

\section{Metafunción Ideacional}

Por otra parte, y desde el análisis de la Metafunción Ideacional, las enunciaciones presentes en los textos se analizaron en función de una matriz construida con los tres componentes de la función de Proceso descrita por Martin \& Rose (2003): Hacer - Significar - Ser.

Cabe señalar que los nombres de los procesos propuestos por Martin y Rose (2003) no son categorías simples y transparentes, pues pueden ser significados de diversas maneras dependiendo de la tradición en la que se posicionan los analistas. Se hace necesario entonces explicitar que, en el contexto de este trabajo, el investigador se sitúa desde una perspectiva que reconoce el discurso como una práctica social (Calsamiglia y Tusón, 1999; Wodak, 2003; Fairclough, 1999; Jäger, 2003). Desde esta perspectiva, no hay una demarcación a priori que permita delimitar y escindir el decir y el hacer, puesto que frecuentemente el decir constituye al mismo tiempo un acto de realización (Austin, 1962). En este sentido, y siguiendo a Austin, una frase performativa no es solamente una declaración.

Así, y para efectos del análisis que se presenta a continuación, el proceso de "Hacer" se aborda desde la perspectiva del acto de habla, en que un decir constituye o da lugar a una performance. Calsamiglia y Tusónseñalan que tales enunciaciones tienen "intenciones, metas o finalidades" [y por lo tanto] despliegan estrategias encaminadas a la 
consecución de esos fines" (1999, p. 16). Este tipo de enunciaciones daría lugar a prácticas curriculares o énfasis particulares en su abordaje.

Por otro lado, el "decir" que forma parte del proceso de "significar" se comprende como aquellas enunciaciones utilizadas principalmente con fines declarativos, para describir o definir sentidos y orientaciones más amplias, y que no necesariamente encuentran su realización en intencionalidades pedagógicas específicas.

La siguiente tabla muestra un ejemplo muy breve a partir de algunos de los textos.

Tabla 4. Extractos de función ideacional de proceso.

\begin{tabular}{|l|l|l|}
\hline Hacer & $\begin{array}{l}\text { Significar (sentir y } \\
\text { decir) }\end{array}$ & $\begin{array}{l}\text { Ser (cualidad, clase, } \\
\text { identidad, existencia) }\end{array}$ \\
\hline - tener una palabra fun- & - Yo siento que está & - (la Universidad \\
dada sobre cómo debe & muy presente la per- & debería ser) experta en \\
ser, cómo más justo debe & manente mirada al & humanidad. \\
ser este sistema & sistema educacional & - Formar es mucho más \\
formar personas capaces & - Creo que quien está & que enseñar fórmulas... \\
de ser sujetos de la & en educación, piensa & es aproximar con la \\
historia & al país. & ciencia y el ejemplo a \\
- hay que reformular las & - El deseo de ir ajus- & los alumnos a un modo \\
preguntas esenciales & tando brechas & de encarar la vida y de \\
- buscar juntos una & & relacionarse con Dios. \\
solución & & - una preocupación dis- \\
- evaluar y sancionar su & & cursiva y real, material, \\
su inequidad (del siste- & & es el énfasis sobre la \\
ma educacional), & & equidad \\
- hablar de la segmenta- & & - Hay un esfuerzo \\
ción social, & & permanente de ser \\
poner eso como reflexión & & sensibles y permeables \\
de los profesores & & a qué es lo que pasa en \\
& & la sociedad \\
\hline
\end{tabular}

A partir del análisis completo de estos elementos surgen tres grandes conclusiones:

1. La opción por la justicia social en el caso estudiado es explícita:

El análisis de los tres textos que surgen de la documentación oficial y de la voz de los académicos entrevistados de esta Universidad da cuenta de 
un interés y adherencia explícita e intencionada por un trabajo académico y formativo cruzado por un involucramiento con problemáticas sociales nacionales. Este interés declarado por un conocimiento y análisis de las situaciones de desigualdad y pobreza en el país da cuenta de un proceso formativo orientado hacia asuntos de justicia social. Así, la opción que mandata los rasgos identitarios de la institución se enuncia y cristaliza en dos dimensiones: una en que se proyecta el carácter institucional, aquello que se establece como misión y carácter de la Universidad (y que aparece como declaraciones de voluntad formativa) y otra que tiene relación con los sentidos y trabajo de los actores que la componen (prescripciones sobre los énfasis, requerimientos, tareas, etc).

A modo de ejemplo, esta primera dimensión se reconoce en el texto del Acta de Fundación de la Universidad, en el que se proyecta como una institución con la misión de "contribuir al desarrollo de un Chile próspero, justo y solidario", proponiendo una pedagogía que "promueve la justicia", y que "forma personas libres", "que se ponen al servicio de Dios y de los hombres". Este foco en aspectos de servicio, progreso y contribución no aparecen como una sugerencia o deseo, sino más bien como delineamiento autoritativo del énfasis institucional, al contar con marcajes semióticos que dan cuenta de oficialidad y de importancia, como los sellos de la Universidad, la Compañía de Jesús y las firmas del entonces Presidente de la República y del Rector.

La segunda dimensión (énfasis y tareas de los participantes) se logra reconocer con mayor claridad en los textos del Discurso de Inauguración pronunciado por el Rector y la entrevista grupal con académicos directivos de la Facultad de Educación.

A modo de ejemplo, el Discurso de Inauguración establece un 'contrato' curricular al describir el tipo de sujeto profesional que forma, y el tipo de relación que establece con el saber: “...los egresados de estas aulas tienen que tener verdadera pasión por la justicia, procurando crear con todo su empeño una sociedad más justa, solidaria y humana”. A continuación, enuncia una tarea que convoca tanto a estudiantes como a docentes: “...es indispensable que se estudien los mecanismos que generan injusticia y que se tenga contacto real con los marginados, con los más pobres". Adicionalmente, el texto proyecta un rasgo actitudinal en sus estudiantes como resultado de este proceso formativo: “... las personas formadas en esta Universidad deberían ser fermento de concordia". 
Por su parte, en el discurso de los académicos también está la opción por una perspectiva de justicia social que aparece como un énfasis formativo traducido en tarea para académicos y estudiantes: “...está en los programas, en el primer año, el tema de comprender complejamente el sistema educacional chileno, evaluar y sancionar su inequidad, hablar de segmentación social, poner eso como tema de reflexión...".

[...] un rol que cualquier profesor o profesora tiene que cumplir [es] tener una palabra fundada sobre cómo deber ser, cómo más justo debe ser este sistema, yo creo que es algo que dentro de todo se intenciona, o sea, por lo menos hay tres o cuatro cursos que tienen esa perspectiva, y eso me parece muy importante" (entrevista grupal con académicos).

2. La opción pro justicia social de la Universidad se traduce en un foco formativo puesto en el desarrollo cognitivo:

El foco de la noción de justica imbricada en la acción formativa de esta institución aparece en su discurso en la descripción de las tareas, atribuciones y sentidos tanto de los académicos como de los profesionales que forma. De acuerdo a los hallazgos del análisis Ideacional y considerando sus Modalidades Enunciativas, los tres textos analizados dan cuenta de que, al referirse al énfasis formativo en justicia social, hay un predominio de selecciones léxicas que describen actos cognitivos o contemplativos.

Así, el Acta de Fundación declara la intención de formar personas "inspiradas en el evangelio" y "sólidamente instruidas en las ciencias". Por su parte, los académicos entrevistados señalan que, en el contexto de cambio societal, en la formación de profesores "tiene que haber una formación de base, de tipo capacidad de análisis, de reflexión sobre la sociedad, de orientación ética". Más aún, se hace evidente el contraste de una mirada de la teoría crítica en educación que "se ha quedado mucho en...compartamos, conversemos..." y la mirada que se ha dado más en esta institución, que es la mirada de "política macro", "una perspectiva de política...que tiene que ver con una crítica a la ciudad, al país como está constituido..." en la que la función de la formación tiene como propósito "meter a los estudiantes en un aparato conceptual que permita seguir leyendo esas cosas" (entrevista grupal con académicos). 
De esta manera, a lo largo de los tres textos, se aprecian descripciones de la formación cuyos focos están en tareas y asuntos como: análisis, interpretación, lectura, estudio, reflexión, conocimiento, evaluación, conciencia. etc, las que difierende otras posibilidades de selecciones y opciones posibles al considerar la educación y la orientación a la justicia social y que se pueden cristalizar en verbos de acción, como implementar, diseñar, cambiar, transformar, discutir, proponer, etc.

Así, el análisis demuestra que parte importante del significado de lo que constituye una formación ligada a la justicia social pasa por operaciones afectivo-mentales principalmente, y menos en disposiciones evaluables por medio de actos.

Esta constatación abre una serie de implicancias curriculares en términos de coherencia interna entre el proyecto formativo de la Universidad y la configuración de sus programas.

\section{Foco en la equidad:}

Un tercer elemento que emerge del análisis y que permite delinear el discurso de justicia social que construyen los textos es la determinación del énfasis de la enseñanza impartida, el que aparece puesto en una preocupación por la equidad.

Esta preocupación se visibiliza de dos maneras en los textos estudiados: la descripción de las tareas e intereses asumidos en el proceso de formación de los futuros profesores y en la selección léxica utilizada para referirse a las orientaciones de la Universidad.

La opción por los asuntos de equidad son mencionados explícitamente tanto en los textos oficiales como en el discurso de los académicos entrevistados.

Al ser consultados acerca de los focos/énfasis de la enseñanza impartida en la Facultad de Educación, los entrevistados señalan que: “...una preocupación discursiva, y real, material, es el énfasis sobre la equidad, sobre los contextos vulnerables, o en la pobreza...”.

Esta opción se logra observar también cuando la institución reconoce como punto de partida que habría una "inequidad endémica de nuestra sociedad" (Discurso de inauguración), y luego en las descripciones que hacen los académicos acerca de los requerimientos del proceso formativo: “...los estudiantes tienen que hacer sus experiencias laborales en contextos vulnerables... y que de ello surjan reflexiones, análisis; se les 
acompaña en ese proceso y eso es intencionado, queremos que conozcan esta realidad...".

Se establece entonces que el modo de operacionalizar la opción por la justicia social es por medio del trabajo con grupos desaventajados, lo que tiene que ver con la realización de prácticas profesionales en lugares pobres, pero también con la incorporación de estudiantes a la carrera de pedagogía, al ser reconocidos como un grupo más vulnerable en términos académicos: “creo que hay una opción fundacional porque los estudiantes, especialmente de pedagogía, que son estudiantes más vulnerables en relación a los estudiantes universitarios tradicionales, vengan acá, porque acá creemos que es justo y democrático que ellos tengan una oportunidad para estudiar" (entrevista grupal con académicos).

En otro orden de temas, los vocablos utilizados en los textos para referirse a los fines de la educación hacen referencia a la preocupación por la pobreza y el desarrollo de actitudes como la solidaridad y la concordia. La situación de vulneración económica es casi la única forma de injusticia mencionada, y los resultados de la formación tienen relación con capacidades empáticas, solidarias y de lectura analítica. Otros tipos de injusticias (sexo, género, etnia, entre otros) y otros resultados formativos en cuanto a la justicia social no aparecen en los textos estudiados.

En su conjunto, estas tres grandes características descritas permiten situar el discurso de justicia social de esta Universidad al interior de un paradigma redistributivo, y describirlo en términos de una orientación socio-política de afirmación (Marion Young, 2000).

El paradigma redistributivo de justicia social -si bien considera no solo bienes, sino también posiciones, accesos y recursos de diversa índole- tiende a concebir los asuntos de justicia como un problema primordialmente de distribución. De ahí que metáforas muy propias de este paradigma aluden a imágenes del tipo "nivelar la cancha", "dar oportunidades", etc. Siguiendo a Marion Young, para el paradigma redistributivo "todas las situaciones en las que la justicia está en cuestión son análogas a la situación de las personas que dividen una cantidad de bienes y comparan la medida de las porciones que los individuos tienen" (2000, p. 36) y luego agrega: "La discusión pública sobre la injusticia social tiende a girar alrededor de las desigualdades de riqueza e ingresos, y de la medida en el que Estado puede o debe mitigar el sufrimiento de la gente pobre" (p.38). 
De este modo, bajo una mirada redistributiva surgen remediales como las llamadas "escuelas efectivas" que buscan asignar en sectores de pobreza una mayor cantidad de contenidos a fin de tender a la equiparación de resultados en pruebas estandarizadas, o bajo el entendido que una mejor preparación académica otorgaría mayores posibilidades de movilidad social.

En su libro "Justice Interruptus", Nancy Fraser (1997) reconoce dos orientaciones políticas al interior del paradigma redistributivo: la de afirmación y la de transformación. Mientras que esta última apunta a una reestructuración profunda de las relaciones de producción (mirada que asocia al Socialismo), la orientación de afirmación toma como tarea la reasignación de bienes, servicios y accesos a los diferentes grupos sociales (lo que asocia con una mirada clásica de Estado de bienestar). Esta postura de justicia social, si bien reconoce la existencia de diferenciaciones de clase social y de estructuras y relaciones sociales desiguales, deja intactas esas estructuras y relaciones que generan desventajas.

La noción redistributiva de justicia social sobre la cual opera la formación de profesores de esta Universidad se reconoce toda vez que su discurso hace alusión a la pobreza (como vulneración principal y foco de las intervenciones), al acceso a un servicio, al otorgamiento de oportunidades, a la ascensión (social o profesional).

Si bien en los textos estudiados aparecen enunciados que podrían dar cuenta de una orientación no solo hacia el conocimiento, sino que hacia la transformación de las situaciones de injusticia, estas resultan esporádicas, minoritarias y sin un correlato práctico en la descripción de las actividades y focos formativos en la formación de profesores.

\section{Síntesis y discusión}

En cuanto al contenido y posicionamiento ideológico del discurso de justicia social de esta institución, su identificación requirió de un análisis micro que considerara una mirada al texto en sí, a las selecciones de palabras con las que enuncia sus actividades formativas y los supuestos que las sustentan.

El análisis Ideacional de las enunciaciones (el modo en que se representan experiencias, acciones y comprensiones) permitió reconocer el posicionamiento de la noción de justicia de la Universidad estudiada en el marco de las racionalidades curriculares levantadas desde Habermas. 
Un primer elemento que surge de este análisis es que la modalidad enunciativa que predomina por sobre la totalidad de enunciaciones es la Epistémica. El aspecto que aparece como central en el modo en que se asume la justicia en la formación es el desarrollo de capacidades y disposiciones basadas en la lectura, análisis y comprensión de la dimensión política de la práctica educativa. Esta opción encuentra su correlato en la función enunciativa deóntica (mandatos, tareas, obligaciones) que aparece intertextualmente en otros documentos ("es indispensable que se estudien los mecanismos que generan injusticia y que se tenga contacto real con los marginados, con los más pobres").

En tanto, desde el análisis de proceso ideacional, se presentanlas enunciaciones utilizadas y que resultan clarificadoras en cuanto al terreno ideológico. Los "haceres" en que se traduce la orientación de justicia social se manifiestan fundamentalmente en actos cognitivos, los que en los textos aparecen como conocer la realidad de desigualdad, evaluar la inequidad, distinguir políticas, analizar, hablar de democratización, leer, desarrollar habilidades de pensamiento, etc. Vale decir, la manera de operacionalizar la noción de justicia en la formación se realiza por medio de una preparación orientada principalmente a la compresión del estado de cosas.

Vale notar que en la perspectiva teórico-metodológica propuesta, el ejercicio analítico puede enfrentar al investigador con desafíos interpretativos que lo comprometen con la necesidad de un posicionamiento y la toma de decisiones concordantes con la "actitud" crítica que el ACD supone. Un ejemplo que refleja esta complejidad del acto de habla en tanto performativo mencionado anteriormente se puede apreciar en el tratamiento de ciertas expresiones que fueron clasificadas en el proceso de "hacer", como "tener una palabra fundada sobre cómo debe ser este sistema" o "hablar de la segmentación social" y "poner eso como reflexión". Aquí, si bien el "tener una palabra" o "hablar" de temáticas de justicia puede ser considerado a primera vista como un proceso de significación (en el decir), podemos apreciar que el contexto en el que se apoyan esas enunciaciones (como su relación intertextual con el resto del discurso de los entrevistados y la documentación oficial del caso estudiado) demuestran que, aunque no siempre refieren a acciones observables propiamente tal, tampoco se refieren a un decir de carácter declarativo (como en el proceso de significar). El decir al que se refieren estos segmentos está relacionado directamente a ciertos énfasis curriculares que 
se traducen en actos que -aunque no siempre externos u observables- se evidencian en una práctica intelectual sostenida e intencional.

En términos curriculares, esta constitución del significado de la justicia social resulta importante de considerar, puesto que en su configuración, el discurso termina siendo constructivo y constitutivo de las maneras en que pensamos, sentimos y actuamos en el mundo. En otras palabras, lo que aprenden los estudiantes de pedagogía y su subsequente acción en el mundo profesional, está fuertmente mediado y modelado por una práctica discursiva que representa el acto docente y a la justicia social de una determinada manera, a saber, que se trata de una forma de pensar, distinguir y analizar situaciones de injusticia social fundamentalmente ligadas a la desigualdad económica. Otros tipos de injustica (como las ligadas al género, orientación sexual, etnia, etc.) no aparecen transparentemente en las enunciaciones, como tampoco un acto formativo que intencione la traducción de esas comprensiones en disposiciones prácticas.

La siguiente tabla (5) da cuenta de una visión sintética de las selecciones léxicas utilizadas para representar la noción de justicia en la formación de profesores.

Tabla 5. Síntesis de representaciones de justicia.

\begin{tabular}{|l|c|l|}
\hline Hacer & Significar (sentir y decir) & $\begin{array}{l}\text { Ser (cualidad, clase, } \\
\text { identidad, existencia) }\end{array}$ \\
\hline - Es indispensable & - siento que está muy presente & - hay una conciencia \\
que se estudien los & la permanente mirada al sis- \\
mecanismos que & tema educacional...el tema & que el 99\% de los \\
generan injusticia. & de comprender compleja- & profesores está aquí \\
- Implica meter a & mente el sistema educacio- & por lo que significa \\
los estudiantes en & nal chileno. & esta Universidad \\
unaparato concep- & - creo que el discurso sobre & y por el proyecto \\
tual que permita & la formación de un profesor & en sí. \\
seguir leyendo esas & analítico, reflexivo, crítico, & - (contribuir a un \\
cosas durante sus & es propio de un grupo de & Chile) próspero, \\
vidas. & universidades que ha hecho & justo y solidario. \\
tener una palabra & esta apuesta. & - fermento de \\
fundada sobre & - creemos que es justo y & concordia. \\
cómo debe ser, & democrático que ellos & - El aprendizaje con- \\
cómo más justo & tengan una oportunidadde & siste en generar más \\
debe ser este & estudiar. & oportunidades de \\
sistema. & - El deseo de ir ajustando & que otro construya \\
& brechas. & su conocimiento. \\
\hline
\end{tabular}




\subsection{Los espacios de posibilidad de una perspectiva de justicia social en el ámbito pedagógico}

Tal como se anuncia al inicio de este artículo, el reconocer que la perspectiva de justicia social no se agota en los planteamientos y acción de las teorías críticas, sino que encuentra desafíos desde posicionamientos de carácter postcríticos, este trabajo estaría incompleto si no considerase, desde aquellos desafíos, una palabra con respecto a lo no dicho en el discurso institucional de esta Universidad en torno a la justicia social y a las posibilidades que suponen esos aspectos silenciados.

Con respecto a "lo dicho", los datos en el análisis señalan que el discurso de justicia social que enuncia la Universidad hace referencia mayoritariamente a aspectos propios de una mirada distributiva, como la preocupación por la pobreza, inequidad en la distribución de bienes y accesos, y conocer los modos en que opera el sistema.

Sin embargo, el discurso guarda silencio con respecto a otros tipos de desigualdades, injusticias y formas de opresión, y que responden a aspectos no distributivos, sino más bien de representación, como las relacionadas a las perspectivas de las minorías y las formas de saber no tradicional (postcolonialismo, teoría queer, multiculturalismo, etnias minoritarias, discapacidad, entre otras).

Son aspectos como estos los que no aparecen en el discurso de justicia social de la institución estudiada, y que llaman la atención porque permiten apreciar los supuestos desde los que se construye su discurso y práctica (estas temáticas no están ausentes porque a alguien "se le olvidó” mencionarlas), y porque permite avanzar en nuevas consideraciones y posibles transformaciones de la práctica de formación de profesores orientada a la justicia social.

Un supuesto importante es que las comprensiones y reflexiones que se dan desde un trabajo exclusivamente enfocado desde aspectos distributivos, podrían estar distorsionadas por los efectos de condiciones y relaciones menos perceptibles a simple vista, y que se relacionan a aspectos de género, sexo, raza, entre otros, que configuran las relaciones de diferencia en lo que se considera bueno, aceptable, conocimiento válido, lo posible, lo necesario, etc.

Desde aquí, surgen una serie de posibilidades de transformación de los discursos y prácticas de justicia social en el currículum de formación de profesores de esta Universidad. 
Una primera aseveración que focaliza la perspectiva de justicia social en el ámbito pedagógico -considerando asuntos de dominación y opresión-es que tradicionalmente el canon del currículum ha hecho pasar por cultura común una cultura en realidad bastante particular: eurocéntrica, blanca, masculina y heterosexual (Da Silva, 2001).

A partir de aquí se origina una serie de cuestionamientos que ya no fijan la justicia como un asunto de acceso a la educación solamente, sino que interrogan las nociones fundantes de la relación educativa: ¿con qué tipo de conocimiento estamos trabajando?, ¿de dónde surge?, ¿por qué este saber y no otro?, ¿cuáles son las implicancias de este modo de saber y de este conocimiento? Este modo de concebir el currículum y la justicia remite a acciones prácticas en dos ámbitos.

Por un lado, la reconsideración deconstructiva de los supuestos pedagógicos y epistémicos con los que se trabaja. Estoconlleva mirar el contenido ideológico de los discursos de conocimiento con los que operamos, su historia y sus implicancias. Así, por ejemplo, Connell (2006) refiere a investigaciones que demuestran las estrechas relaciones entre el desarrollo de la física moderna y el capitalismo moderno y el género (el saber de las ciencias "naturales" de occidente como producto de una acción dominante de hombres sobre el mundo social y natural).

De la misma manera, desde una perspectiva descolonial, Walter Mignolo advierte que los modos de ser, hacer y decir en América se dan -a partir del siglo XVII- al interior del marco de una "matriz colonial de poder", que como parte del metarelato imperial, define los límites de lo decible, lo posible y lo deseable en cuatro dominios principales: economía, autoridad, género y sexualidad, y subjetividad y conocimiento (Mignolo, 2010). En ese contexto, una mirada de justicia ha de manifestarse en un acto consciente de desenganche de la matriz, y el trabajo a partir de un conocimiento autónomo, en contraposición al "sentido común" de lo desigual y la jerarquía implícita en los saberes coloniales.

En esta tarea de reconceptualización deconstructiva, el concepto de "justicia curricular" expuesto por Connell (2006) resulta de interés al desarrollar tres principios para operacionalizar estas decisiones epistémicas.

1. Los intereses de los menos favorecidos: enfocar el conocimiento desde los grupos oprimidos. Ejemplo: Plantear los temas económicos desde 
la situación de los pobres, las cuestiones territoriales y raciales desde la perspectiva de los indígenas, las temáticas de género y sexualidad desde la perspectiva de las mujeres y homosexuales.

2. Participación y escolarización común: Operacionalizar las declaraciones de valores y objetivos en formas de acción concreta en la legitimación de la igualdad. Supone prácticas no jerarquizadas de cooperación y toma de decisiones. Descarta cualquier tipo de selección, de evaluación competitiva y de mecanismos de agrupamiento y clasificación.

3. Producción histórica de igualdad: Foco en criterios contrahegemónicos y de ciudadanía participativa. Elaboración de juicios estratégicos sobre cómo favorecer la igualdad. Esto incluye la preparación de prácticas curriculares que aumenten la capacidad de las personas para realizar acciones de mejora y transformación.

Por otra parte, la segunda acción práctica a la que conduce una perspectiva postcritica acerca del currículum tiene que ver con las decisiones que se tomen, las que pueden finalmente resolverse en la optimización, ajuste o rediseño de la propuesta formativa.

En términos prácticos de diseño curricular, para el caso de esta Universidad estudiada, la unión entre las creencias (ideologías) y la acción podría ser operacionalizada por medio de un enfoque de desarrollo de competencias. Este enfoque, aunque no exento de aspectos criticables, puede proveer una pauta organizadora que permite visualizar más claramente en el diseño la manera en que cada aspecto que compone el perfil del futuro profesional es intencionado por medio de dispositivos de formación y evaluación. De modo particular, los procesos formativos y evaluativos ponen la mirada sobre las capacidades de los estudiantes para generar desempeños comprensivos complejos, vale decir, ya no solo un conocimiento declarativo, sino procedimental.

El desarrollo de este tipo de disposiciones y competencias para la justicia social se posiciona como una plataforma indispensable para el trabajo dialéctico entre esquemas de interpretación teórica y la acción transformativa en situaciones reales.De esta manera, habilitamos a los sujetos para la comprensión, pero también para la acción comprometida en la transformación de sus contextos locales, utilizando los espacios de los que disponen en los diversos niveles de concreción curricular. No olvidemos la advertencia de Albert Camus: "la tiranía totalitaria no se 
edifica sobre las virtudes de los totalitarios, sino sobre las faltas de los demócratas".

\section{Referencias bibliográficas}

Álvarez, G. (2001). Textos y discursos. Concepción: Editorial Universidad de Concepción.

Austin, J. (1962). How to do things with words. Harvard University Press. Ávila, N. y Medina, L. (2012). El análisis Dialógico del Discurso (ADD) y la teoría de la enunciación: descubriendo la tensión dialógica en los discursos de profesores secundarios chilenos. Estudios de Psicología, (33), 231-247.

Calsamiglia, H. y Tusón, A. (1999). Las cosas del decir. Barcelona: Ariel.

Cochran-Smith, M. (2004). Walking the road: race, diversity and social justice in teacher education. New York: Teachers College, Columbia University.

Cochran-Smith, M. (2008). Toward a theory of teacher education for social justice. Boston College.

Connell, R. (2006). Escuelas y justicia social. Madrid: Morata.

Da Silva, T. (2001). Espacios de Identidad: Nuevas visiones sobre el currículum. Barcelona: Octaedro.

Fairclough, N. (1999). Critical Discouse Analysis. The Critical Study of Language. London: Longman.

(2003). El análisis crítico del discurso como método para la investigación en ciencias sociales. En Wodak, R. y Meyer, M. (Eds.). Métodos de Análisis Crítico del Discurso. Barcelona: Gedisa, 61-99

(2008). El análisis crítico del discurso y la mercantilización del discurso público: las universidades. Discurso y Sociedad, 2(1), 170-185

Foucault, M. (1979). La arqueología del saber. México: Siglo XXI.

Fraser, N. (1997). Justice interruptus: critical reflections of the "post socialist" condition. New York: Routledge.

Grundy, S. (1998). Producto o praxis del curriculum. Madrid: Morata.

Habermas, J. (1972). Knowledge and human interest. Beacon Press. 
Habermas, J. (1974). Theory and practice. Beacon Press.

Jäger, S. (2003). Discurso y conocimiento: aspectos teóricos y metodológicos de la crítica del discurso y del análisis de dispositivos. En Wodak, R. yMeyer, M. (Eds). Métodos de Análisis Crítico del Discurso. Barcelona: Gedisa, 61-99.

Marion Young, I. (2000). La justicia y la política de la diferencia. Ediciones Cátedra, Universitat de València.

Martin, J. y Rose, D. (2003). Working with discourse: meaning beyond the clause. Continuum.

. (2007). Working with discourse: meaning beyond the clause. Second Edition - Continuum.

McDonald, M. (2005). The integration of social justice in Teacher education: dimensions of prospective Teacher's opportunities to learn. In Journal of Teacher Education, SAGE Publications, 56, (5), 418-435.

McInerney, P. (2012). Rediscovering Discourses of Social Justice: Making Hope Practical en Down, B. ySmyth, J. (Eds.). Critical Voices in Teacher Education, Explorations of Educational Purpose, 22, 27-43.

Mignolo, W. (2010). Desobediencia Epistémica: retórica de la modernidad, lógica de la colonialidad y gramática de la descolonialidad. Buenos Aires: Del Signo.

Murillo, F. (2011). El rol de la reflexión al interior de un programa de formación inicial docente: el tránsito hacia un profesional crítico y reflexivo.Sembrando Ideas, (5), 37-45.

Torres, J. (1998). El curriculum oculto. España: Morata.

Van Dijk, T. (2003). La multidisciplinariedad del análisis critico del discurso: un alegato en favor de la diversidad. En Wodak, R. y Meyer, M. (Eds.). Métodos de Análisis Crítico del Discurso (pp. 61-99). Barcelona: Gedisa.

Van Leeuwen, T. (2008). Discourse and Practice: New tools for Critical Discourse Analysis. New York: Oxford University Press.

Volosinov, V. (1986). Marxism and the Philosophy of Language. Cambridge, MA: Harvard University Press.

Wertsch, J. (2002). La mente en acción. Buenos Aires: Aique. 
Wodak, R. y Meyer, M. (2003). Métodos de Análisis Crítico del Discurso. Barcelona: Gedisa.

Zeichner, K. (2009). Teacher Education and the Struggle for Social Justice. New York: Routledge. 